Int. J. Electrochem. Sci., 13 (2018) 10809 - 10820

\title{
Novel Ginger-like Morphology of Barium Molybdate: A Promising Electrocatalyst for the Detection of Neurotransmitter Dopamine
}

\author{
Periyasamy Sundaresan ${ }^{1}$, Y Chi Chen $^{1}$, Shen-Ming Chen ${ }^{1, *}$, Tse-Wei Chen ${ }^{1,2}$, Petchi Latha ${ }^{3}$, \\ and Bih-Show Lou ${ }^{4,5^{*}}$, \\ ${ }^{1}$ Electroanalysis and Bioelectrochemistry Lab, Department of Chemical Engineering and \\ Biotechnology, National Taipei University of Technology, No.1, Section 3, Chung-Hsiao East Road, \\ Taipei 106, Taiwan, ROC. \\ ${ }^{2}$ Research and Development Center for Smart Textile Technology, National Taipei University of \\ Technology, No. 1, Section 3, Chung-Hsiao East Road, Taipei 106, Taiwan, ROC. \\ ${ }^{3}$ Department of Chemistry, VHNSN College, Virudhunagar-626001, Tamil Nadu, India. \\ ${ }^{4}$ Chemistry Division, Center for General Education, Chang Gung University, Taoyuan, Taiwan, \\ ${ }^{5}$ Department of Nuclear Medicine and Molecular Imaging Center, Chang Gung Memorial Hospital, \\ Taoyuan, Taiwan \\ *E-mail: smchen78@ms15.hinet.net, blou@mail.cgu.edu.tw
}

doi: $10.20964 / 2018.11 .59$

Received: 20 July 2018 / Accepted: 22 August 2018 / Published: 1 October 2018

In this work, we have report a novel electrochemical sensor for the selective detection of dopamine (DA) based on ginger-like morphology of barium molybdate $\left(\mathrm{BaMoO}_{4} ; \mathrm{BaM}\right)$ modified screen printed carbon electrode (SPCE). The ginger-like BaM was prepared through a simple co-precipitation technique and its physiochemical properties were systematically investigated by various analytical and spectroscopic techniques such as X-ray diffraction (XRD), Raman, field emission-scanning electron microscopy (FE-SEM) and energy-dispersive X-ray spectroscopy (EDX). Furthermore, the as-prepared ginger-like $\mathrm{BaM}$ was effectively investigated for the sensitive and selective electrochemical determination of DA. The ginger-like BaM/SPCE shows a reversible electrochemical behavior with superior current response for DA detection. The $\mathrm{BaM}$ catalyst played a significant role to electrochemical detection of DA, as a results very low detection limit $(0.021 \mu \mathrm{M})$, wide linear response range $(0.1-266 \mu \mathrm{M})$, well sensitivity $\left(0.35 \mu \mathrm{A} \mu \mathrm{M}^{-1} \mathrm{~cm}^{-2}\right)$ and good selectivity in the presence of common metal ions and biological compounds. This study provides a novel idea for the fabrication of binary metal oxides and their potential application in electrochemical sensor and biosensor.

Keywords: Binary metal oxide, Ginger-like, Barium molybdate, Neurotransmitter, Dopamine, Electrochemical sensor 


\section{FULL TEXT}

(C) 2018 The Authors. Published by ESG (www.electrochemsci.org). This article is an open access article distributed under the terms and conditions of the Creative Commons Attribution license (http://creativecommons.org/licenses/by/4.0/). 